\title{
TESTS DE DISSOLUCIÓ IN VITRO DE NICOTINA EN PEGATS TRANSDÈRMICS
}

\author{
PEdREIRA Rincón, JÚlial; ${ }^{1}$ PÉREZ RÀFols, ANNA; \\ BoIX MONTAÑ́́s, ANTONIO \\ Unitat de Biofarmàcia i Farmacocinètica, \\ Facultat de Farmàcia i Ciències de l'Alimentació, Universitat de Barcelona \\ Av. Joan XXIII, 27, 08028 Barcelona
}

\begin{abstract}
This study was carried out at the University of Barcelona's biopharmaceutics and pharmacokinetics laboratory. Several in vitro dissolution tests of nicotine transdermal patches (Nicotinell $®$ ) were performed using a pharmacopoeial Paddle-over-disk dissolution apparatus to study the effect that extreme $\mathrm{pH}$ conditions and different agitation rates could have over drug release. Various dissolution models were then matched to the experimental data using the DDsolver add-in program for Microsoft Excel, in order to find the most suitable descriptive equation. This was provided by the Peppas-Sahlins model, with $m=0.5$, indicating that the release profile followed a dual mechanism of both erosion and diffusion to release the drug. In order to confirm this model selection several amodelistic parameters, such as the $f 2$ similarity index were also calculated. The results show how the dissolution rate improves as a function of $\mathrm{pH}$ and, to a lesser extent, with an increase in agitation rate.
\end{abstract}

Keywords: nicotine, release conditions, transdermal route,

\section{Resumen}

El siguiente estudio se ha llevado a cabo en el Laboratorio de Biofarmacia y Farmacocinética de la Universidad de Barcelona.

En este proyecto se han realizado diferentes test de disolución in vitro con parches transdérmicos de nicotina (Nicotinell@) utilizando el aparato Hanson S-8 de disolución, con el objetivo de estudiar el efecto que condiciones extremas de pH del medio de disolución y la velocidad de agitación pueden tener sobre la liberación del fármaco.

Posteriormente, diferentes modelos de disolución se han ajustado a los resultados obtenidos utilizando el complemento de Microsoft Excel DDsolver para encontrar el modelo más adecuado a nuestros resultados. Este modelo ha sido el de Peppas-Sahlins con $m=0,5$, e indicamos que los datos obtenidos siguen un mecanismo de erosión y difusión para realizar la disolución. Se ha confirmado la aceptabilidad de la decisión mediante parámetros amodelísticos como el índice $f 2$ de similitud.

Los resultados obtenidos muestran que la velocidad de disolución se ve mejorada a pH3 y que, a medida que se aumenta la velocidad de agitación, la velocidad de disolución se incrementa.

Palabras clave: nicotina, liberación transdérmica.

\section{Resum}

L'estudi següent s'ha dut a terme al Laboratori de Biofarmàcia i Farmacocinètica de la Universitat de Barcelona.

En aquest projecte s'han fet diferents tests de dissolució in vitro de nicotina en pegats transdèrmics (Nicotinell $®$ ) utilitzant l'aparell Hanson S-8 de dissolució, a fi d'estudiar l'efecte que condicions extremes de pH del medi de dissolució i la velocitat d'agitació poden tenir sobre l'alliberació del fàrmac.

Posteriorment, diversos models de dissolució s'han ajustat als resultats obtinguts utilitzant el complement de Microsoft Excel DDSolver per tal de trobar el model més adequat als nostres resultats. Aquest model ha estat el de

\footnotetext{
${ }^{1}$ Graduada en farmàcia (juliapedreirarincon@gmail.com)
} 
Peppas-Sahlins amb $m=0,5$, i indiquem que les dades obtingudes segueixen un mecanisme d'erosió i difusió per dur a terme la dissolució. S'ha confirmat l'acceptabilitat de la tria mitjançant diferents paràmetres amodelístics, com ara l'índex $f 2$ desemblança.

Els resultats obtinguts mostren que la velocitat de dissolució es veu millorada a pH 3 i que a mesura que s'augmenta la velocitat d'agitació, augmenta la velocitat de dissolució.

Paraules clau: nicotina, alliberació transdèrmica.

\section{Introducció}

\subsection{Absorció de nicotina}

La nicotina és un compost orgànic, alcaloide principal dels productes a base de tabac. És un agonista del receptor nicotínic als sistemes nerviosos perifèric i central. En terapèutica s'utilitza per a teràpies substitutives de nicotina (TSN).

Es tracta d'una base dèbil, amb una pKa (proteïna-cinasa A) de 8,0 (AEMPS, 2019) i una altra de 3,1 . Per tant, es pot trobar en forma ionitzada o no ionitzada, depenent del pH del medi, i en proporcions quantificables segons l'equació de Henderson-Hasselbalch, cosa que condicionarà l'absorció posterior.

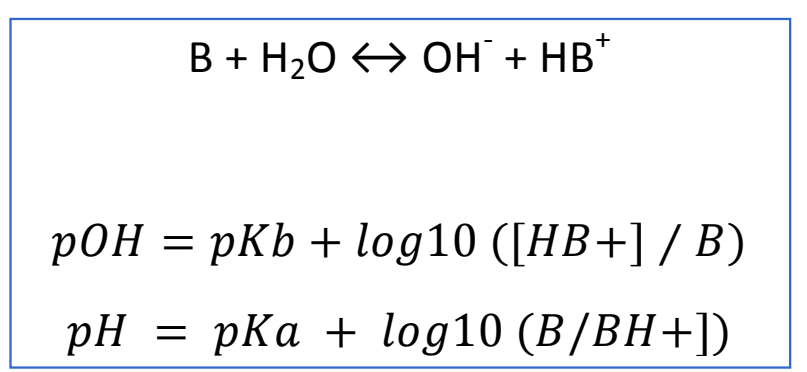

Figura 1. Equilibri base dèbil segons Henderson Hasselbalch equació.

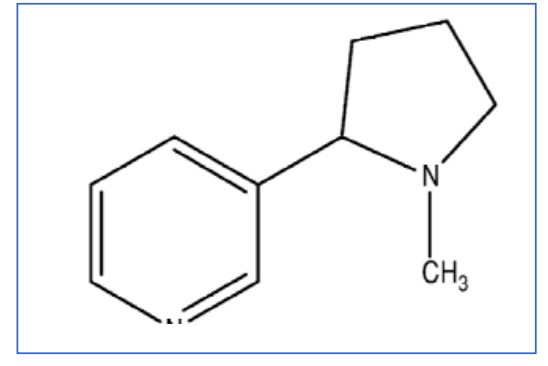

Figura 2. Molècula de nicotina (Mørck i Nielsen i Rømer Rassing, 2002).

Els pegats transdèrmics són formes de dosificació d'alliberació sostinguda i tenen l'avantatge de mantenir la concentració de fàrmac en sang a nivells terapèutics mitjançant una alliberació perllongada en un període de temps que permet una administració més espaiada que la via oral (Costa i Lobo, 2001). En aquest cas, la nicotina s'absorbeix directament a través de la pell i passa a la circulació sistèmica. La velocitat d'alliberació de nicotina es controla mitjançant la permeabilitat de la pell; la velocitat de difusió, a través d'una matriu de polímer, i/o la velocitat de pas, a través de la membrana (Benowitz et al., 2009).

La seva absorció a través de membranes biològiques es produeix generalment per difusió passiva i depèn, per tant, del pH (Mørck Nielsen i Rømer Rassing, 2002). Com a base dèbil (figura 1), en un medi alcalí l'equilibri es desplaçarà cap a la dreta i, per tant, la molècula no ionitzada travessarà les cèl·lules per via transcel·lular. En un ambient més àcid, l'equilibri es desplaçarà cap a l'esquerra. A la molècula mono o biprotonada li costarà més travessar les membranes i, si ho fa, serà per una via més hidrofílica o paracel-lular (Mørck Nielsen i Rømer Rassing, 2002).

Els primers nivells detectables de nicotina d'aquests pegats transdèrmics s'observen després d'una o dues hores després de l'aplicació. Les concentracions plasmàtiques augmenten gradualment fins a arribar a concentracions estacionàries al cap de deu hores de l'aplicació (AEMPS, 2019).

La biodisponibilitat absoluta del pegat, en comparació amb la perfusió intravenosa de nicotina, és d'aproximadament el 77\% (AEMPS, 2019). 


\subsection{Descripció de l’aparell de dissolució}

En la farmacopea Europea (Council of Europe, European Pharmacopeia, 2018) trobem diferents mètodes per avaluar l'alliberació de fàrmac des de formes sòlides, entre els quals hem vist que la millor opció era fer servir l'aparell número 5 (Li M. i Tan H., 2019), que consisteix en una modificació de l'aparell número 2.

\section{Aparell número 5: Paddle apparatus over disc}

El muntatge d'aquest aparell consisteix en un sistema de vasos de vidre segons la figura 3, un element agitador format per un sistema de pales (una per a cada vas) unides a un eix de rotació, un motor que ens donarà la velocitat constant de rotació de les pales i un bany d'aigua per mantenir el sistema a temperatura constant i reproduïble.

Els vasos estan parcialment submergits al bany, que, en el cas de pegats transdèrmics, està fixat a $32 \pm 0,5^{\circ} \mathrm{C}$. El vas és cilíndric amb una base hemisfèrica inferior i d' $1 \mathrm{~L}$ de capacitat, entre $160 \mathrm{i}$ $210 \mathrm{~mm}$ d'alçada i de 98 a $106 \mathrm{~mm}$ de diàmetre interior. Pot tenir una coberta ajustada que permet retardar el procés d'evaporació.

L'eix de rotació de les pales ha d'estar posicionat de manera que el seu eix no sigui superior a $2 \mathrm{~mm}$ en qualsevol punt de l'eix vertical del vas i giri suaument sense oscillacions significatives que puguin afectar els resultats.

El dispositiu de regulació de la velocitat permet seleccionar la velocitat de rotació de l'eix i mantenir-la a una velocitat determinada amb una variació de $\pm 4 \%$.

Els components de l'eix i de l'element agitador han d'estar fabricats en acer inoxidable, tipus 316 o similar. Es permet que la unitat de dosificació s'enfonsi al vas abans de començar la rotació.

En el cas dels pegats transdèrmics es recomana utilitzar discs amb una malla d'acer inoxidable (SSDA) amb una obertura de $125 \mathrm{mcm}$. L'SSDA manté el sistema a la part baixa del vas, de manera que minimitza qualsevol volum mort entre l'SSDA i el cul del vas. L'SSDA aguanta el pegat amb la superfície d'alliberació superior i parallela a la part inferior de la pala. La distància ha de ser de $25 \pm 2 \mathrm{~mm}$ entre la part baixa de la pala i la superfície de l'SSDA i s'ha de mantenir durant el test (Council of Europe, European Pharmacopeia, 2018).

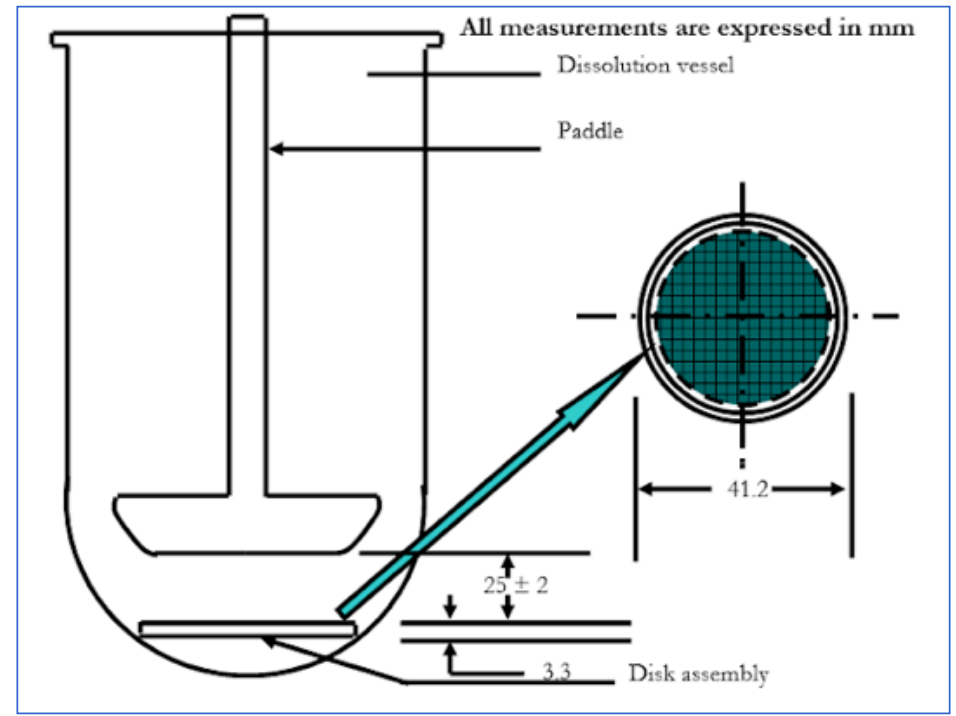

Figura 3. Apparatus 5 paddle over disk, en mm (Dissolution apparatus (paddle overdisk), no date). 


\subsection{Models matemàtics de dissolució}

Hi ha moltes teories o models cinètics per descriure i representar el perfil de dissolució de fàrmacs, tant de dissolució immediata com de dissolució modificada.

Tal com s'explica a l'article «Modeling and comparison of dissolution profiles» (Costa, Manuel i Lobo, 2001), trobem diferents equacions o models que ens poden representar la dissolució de fàrmacs en diferents formes farmacèutiques que comentarem tot seguit.

TAULA 1. MODELS MATEMÀTICS DE DISSOLUCIÓ DE FÀRMAC.

\begin{tabular}{|c|c|c|}
\hline Model matemàtic & Representació matemàtica & $\begin{array}{l}\text { Tipus d'alliberació } \\
\text { que representa }\end{array}$ \\
\hline Cinètica d'ordre 1 & $\begin{array}{l}Q_{t}=Q_{0} \mathrm{e}^{-K_{1} t} \\
\text { on Q1 és la quantitat de fàrmac } \\
\text { alliberat en funció del temps ( } \mathrm{t}) \text {, } \\
\mathrm{Q} 0 \text { és la quantitat de fàrmac } \\
\text { inicial a la solució i K1 és la } \\
\text { constant de primer ordre. }\end{array}$ & $\begin{array}{l}\text { Les fórmules farmacèutiques que } \\
\text { generen aquest perfil de dissolució } \\
\text { solen consistir en matrius de fàrmacs } \\
\text { solubles, que s'alliberen d'una manera } \\
\text { proporcional a la quantitat que es } \\
\text { manté a l'interior. }\end{array}$ \\
\hline Model de Weibull & $\begin{array}{l}m=1-\exp \left[\frac{-\left(t-T_{i}\right)^{b}}{a}\right] \\
\text { on } T \text { representa el temps de } \\
\text { retard abans de l'inici del procés i } \\
\text { en la majoria dels casos és zero. El } \\
\text { paràmetre } b \text { pot tenir diferents } \\
\text { valors, en el cas d'una corba } \\
\text { exponencial }(b=1) \text {, una curvatura } \\
\text { sigmoide ascendent seguida d'un } \\
\text { punt d'inflexió }(b>1) \text { o una corba } \\
\text { parabòlica amb una inclinació } \\
\text { inicial més alta i després } \\
\text { exponencial. El paràmetre } a \\
\text { defineix l'escala de temps del } \\
\text { procés i es pot substituir pel } \\
\text { temps de dissolució }(T d) b, \text { que ens } \\
\text { dona més informació i representa } \\
\text { el temps per alliberar el } 63,2 \% \\
\text { de fàrmac. }\end{array}$ & $\begin{array}{l}\text { És una equació descriptiva, no } \\
\text { mecanística. }\end{array}$ \\
\hline Model de Higuchi & $\begin{array}{l}f_{t}=K_{H} t^{1 / 2} \\
\text { on } K_{H} \text { és la constant de dissolució } \\
\text { de Higuchi. }\end{array}$ & $\begin{array}{l}\text { Útil per a fàrmacs solubles en aigua o } \\
\text { poc solubles incorporats a matrius } \\
\text { semisòlides i/o sòlides. } \\
\text { Descriu l'alliberació de fàrmac com un } \\
\text { procés de difusió depenent de l'arrel } \\
\text { quadrada del temps. Es pot usar per } \\
\text { descriure la dissolució de diferents } \\
\text { formes d'alliberació modificada, com } \\
\text { ara sistemes transdèrmics i comprimits } \\
\text { amb matrius de fàrmacs solubles. }\end{array}$ \\
\hline
\end{tabular}




\begin{tabular}{|c|c|c|}
\hline Model matemàtic & Representació matemàtica & $\begin{array}{l}\text { Tipus d'alliberació } \\
\text { que representa }\end{array}$ \\
\hline $\begin{array}{l}\text { Model de Hixson- } \\
\text { Crowell }\end{array}$ & $\begin{array}{l}\text { Aquest model reconeix que l'àrea } \\
\text { regular de les partícules és } \\
\text { proporcional a l'arrel cúbica del } \\
\text { seu volum: } \\
W_{0}^{1 / 3}-W_{t}^{1 / 3}=K_{s} t \\
\text { on } W_{o} \text { és la quantitat inicial de } \\
\text { fàrmac a la forma farmacèutica i } \\
W_{t} \text { és la quantitat romanent de } \\
\text { fàrmac des d'un temps } t \text {. Ks és la } \\
\text { constant d'incorporació de la } \\
\text { relació superfície-volum. }\end{array}$ & $\begin{array}{l}\text { Es pot aplicar a formes farmacèutiques } \\
\text { on la dissolució es produeix en plans } \\
\text { que són paral.lels a la superfície de la } \\
\text { droga si les dimensions disminueixen } \\
\text { proporcionalment, de manera que la } \\
\text { forma geomètrica inicial es mantingui } \\
\text { constant a tots els temps. } \\
\text { Quan s'usa aquest model, s'assumeix } \\
\text { que la taxa d'alliberació és limitada per } \\
\text { la taxa de dissolució de les partícules de } \\
\text { fàrmac, i no per la difusió que es podria } \\
\text { produir a través de la matriu } \\
\text { polimèrica. }\end{array}$ \\
\hline $\begin{array}{l}\text { Model Korsmeyer- } \\
\text { Peppas }\end{array}$ & $\begin{array}{l}f_{t}=a t^{n} \\
\text { on } a \text { és la constant que incorpora } \\
\text { característiques estructurals i } \\
\text { geomètriques de la forma de } \\
\text { dosificació de fàrmacs, } n \text { és } \\
\text { l'exponent d'alliberació, indicatiu } \\
\text { del mecanisme d'alliberació, i } f_{t} \\
\text { és } M_{t} M_{\infty} \text { (fracció de fàrmac } \\
\text { alliberat). }\end{array}$ & 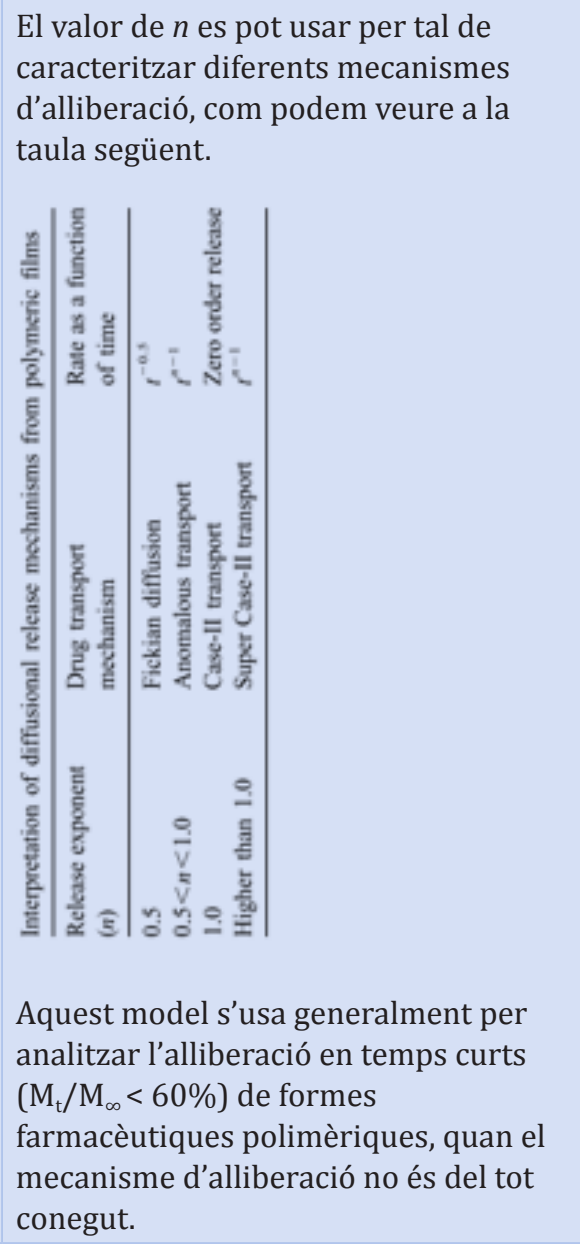 \\
\hline
\end{tabular}




\begin{tabular}{|c|c|c|}
\hline Model matemàtic & Representació matemàtica & $\begin{array}{l}\text { Tipus d'alliberació } \\
\text { que representa }\end{array}$ \\
\hline Model Hopfenberg & $\begin{array}{l}\frac{M_{t}}{M_{\infty}}=1-\left[1-\frac{k_{0} t}{C_{0} a_{0}}\right]^{n} \\
\text { on } M_{t} \text { és la quantitat de fàrmac } \\
\text { dissolt en funció del temps }(t), M_{\infty} \\
\text { és el total de quantitat de fàrmac } \\
\text { dissolt quan la forma farmacèutica } \\
\text { està exhausta, } M_{t} / M_{\infty} \text { és la fracció } \\
\text { de fàrmac dissolt, } K_{o} \text { és la constant } \\
\text { d'erosió, } C_{0} \text { és la concentració } \\
\text { inicial de fàrmac a la matriu i } a_{0} \text { és } \\
\text { el radi inicial de l'esfera o cilindre } \\
\text { o el gruix mitjà d'una placa. }\end{array}$ & $\begin{array}{l}\text { Aquest model descriu l'alliberació de } \\
\text { fàrmac a les formes farmacèutiques o } \\
\text { dispositius d'alliberació per erosió de la } \\
\text { superfície amb diverses geometries. } \\
\text { El valor de } n \text { serà } 1,2 \text { o } 3 \text { per a una } \\
\text { placa, un cilindre o una esfera, } \\
\text { respectivament. }\end{array}$ \\
\hline Model quadràtic & $F=100 *\left(k 1 * \mathrm{t}^{2}+k 2 * t\right)$ & $\begin{array}{l}\text { És una equació descriptiva, no } \\
\text { mecanística. }\end{array}$ \\
\hline Model Peppas i Sahlin & $\begin{array}{l}\frac{M_{t}}{M_{\infty}}=k_{1} t^{m}+k_{2} t^{2 m} \\
\text { on el primer terme es regeix per } \\
\text { la llei de Fick i el segon terme, pel } \\
\text { Case-II d'alliberació relaxacional. } \\
\text { El coeficient } m \text { és un exponent } \\
\text { purament fickià per a qualsevol } \\
\text { forma geomètrica d'alliberació } \\
\text { controlada (Peppas i Sahlin, } \\
\text { 1989). }\end{array}$ & $\begin{array}{l}\text { Descriu l'alliberació resultant de la } \\
\text { combinació de dos mecanismes } \\
\text { d'alliberació: primer una alliberació } \\
\text { més ràpida que segueix la llei de Fick a } \\
\text { causa del gradient químic i, en segon } \\
\text { lloc, pel Case-II l'alliberació relaxacional } \\
\text { és el mecanisme de transport de } \\
\text { fàrmacs associat a l'estrès i la transició } \\
\text { d'estat en polímers hidròfils que } \\
\text { s'inflen d'aigua dels fluids biològics } \\
\text { (Peppas i Sahlin, 1989). }\end{array}$ \\
\hline
\end{tabular}

\subsection{Selecció del millor mètode de dissolució}

Per seleccionar quin model s'ajusta millor, podem usar diversos paràmetres quantitatius, com el coeficient de determinació $\left(R^{2}\right)$, el coeficient de correlació $(R)$, la suma dels quadrats residuals (SSR), l'error quadràtic mitjà $(M S E)$, el criteri d'informació d'Akaike (AIC) i la probabilitat F-ratio. Per la seva simplicitat de càlcul i robustesa, hem escollit el coeficient de correlació (Robs-pred) i el criteri d'informació d'Akaike.

\section{- Coeficient de correlació (Robs-pred)}

El coeficient de correlació és una mesura de regressió per quantificar el grau de variació de la correlació lineal existent entre dues variables: $X$ (temps) i $Y$ (quantitat). És un paràmetre que pot variar entre -1 i 1 , i 1 és, en valor absolut, un ajust estricte al model; així, el valor més proper a 1 serà el model que s'ajusti millor.

$$
\rho x y=\frac{\operatorname{Cov}(x ; y)}{\sigma(x) \sigma(y)}
$$

Equació 1. Coeficient de correlació (Robs-pred). 
Edusfarm 11-12 (2019-2020), 111-134

ISSN: $1886-6271$

- Criteri d'informació d'Akaike (AIC)

El criteri d'informació d'Akaike és una mesura de bondat d'ajust basada en la màxima simplicitat del descriptor: el model associat amb el valor més petit de AIC és considerat el que s'ajusta millor.

$$
\mathrm{AIC}=n \times \ln (\mathrm{WSSR})+2 \times p
$$

Equació 1. Criteri d'informació d'Akaike (Costa, Manuel i Lobo, 2001).

on $n$ és el nombre de punts de dades experimentals, WSSR és la suma de quadrats residuals ponderada i $p$ és el nombre de paràmetres del model.

\subsection{Paràmetres model independents}

Altres paràmetres usats per caracteritzar les corbes d'alliberació independents del model cinètic són, per exemple, l'àrea sota la corba (MDT) o temps mitjà de dissolució, i tx\% o temps de dissolució.

- MDT

L'MDT o mean dissolution time és el temps mitjà que tarden a dissoldre's el 50\% de les molècules de la dosi coneguda. Es pot calcular amb l'equació següent:

$$
M D T=\frac{\sum_{j=1}^{n} \hat{t}_{j} \Delta M_{j}}{\sum_{j=1}^{n} \Delta M_{j}}
$$

Equació 3. Mean dissolution time (Costa, Manuel i Lobo, 2001).

on $\mathrm{j}$ és el nombre d'ordre de cada mostra, $n$ és el temps de mostra de la dissolució, $t_{j}$ és el moment del punt mitjà entre $t_{j} \mathrm{i} t_{j-1}, \mathrm{i} \Delta M_{j}$ és la quantitat addicional de fàrmac dissolt entre $t_{j} \mathrm{i} t_{j-1}$.

- AUC

L'AUC o area under the curve és l'àrea sota la corba que correspon a la integral de la concentració de plasma d'un fàrmac enfront d'un interval de temps definit.

Es defineix per l'equació següent:

$$
\mathrm{AUC}=\sum_{i=1}^{n} \frac{\left(t_{i}-t_{i-1}\right)\left(y_{i-1}+y_{i}\right)}{2}
$$

Equació 4. Area under the curve (Zhang et al., 2010).

L'AUC i l'MDT són paràmetres descriptius que hem fet servir per comparar les diferents condicions experimentals.

- $\mathrm{T} 75$

$T_{x \%}$ correspon al temps necessari per a l'alliberació de determinat percentatge de fàrmac. El temps de mostreig correspon a la quantitat de fàrmac dissolt en un temps $\left(t_{x \min }\right)$.

Per exemple, el T75 és el temps que tarda a estar en solució la fracció de fàrmac que correspon al $75 \%$ de la Q24hores. 


\subsubsection{Comparació del model independent de perfils de dissolució}

La bioequivalència significa que dos productes farmacèutics, quant a la taxa i l'abast d'absorció, no mostren diferències significatives quan s'administren a la mateixa dosi en condicions similars (Rescigno, 1992). Prèviament a un assaig de bioequivalència, cal assegurar que els perfils de dissolució siguin similars. El paràmetre F2 és habitual per demostrar-ho.

\section{Factor de similitud $f_{2}$}

El factor de similitud és un dels mètodes més senzills de comparació entre dos perfils de dissolució (Vinod P. Shah et al., 1999). El valor de $f_{2}$ és una transformació logarítmica de la suma dels errors quadrats de les diferències entre el test $T_{j}$ i el producte de referència $R_{j}$ a tots els temps (Costa, Manuel i Lobo, 2001).

$$
f_{2}=50 \times \log \left\{\left[1+(1 / n) \sum_{j=1}^{n} w_{j}\left|R_{j}-T_{j}\right|^{2}\right]^{-0.5} \times 100\right\}
$$

Equació 2. Factor de similitud (8).

on $w_{j}$ és un factor opcional de pes. (L'equació que proposa la FDA i l'EMA no tenen en compte aquest valor.)

Aquest paràmetre es pot aplicar a corbes de comprimits o de pegats transdèrmics. Pren valors de 0 a 100 i es considera apte si és superior a 50, que representa una variació experimental del $10 \%$ entre corbes d'alliberació.

\section{Objectius}

L’objectiu d'aquest treball és principalment:

1. Comparar els efectes de les diferents variables experimentals que s'han d'estudiar $(\mathrm{pH} \mathrm{i}$ velocitat de rotació de les pales) i trobar una relació entre elles.

2. Postular un mecanisme d'alliberació del fàrmac en funció de l'equació que millor descrigui els resultats experimentals.

Els objectius secundaris són:

- Dissenyar correctament una experiència de dissolució amb l'aprenentatge del funcionament de l'aparell 5 de dissolució i controlar totes les variables.

- Analitzar i recollir els resultats obtinguts de l'experiència amb l'ajuda d'un espectrofotòmetre.

- Tractar les dades amb un programa de regressió no lineal i fer un estudi de selecció de model trobant els paràmetres més representatius.

- Confirmar estadísticament l'acceptabilitat dels resultats obtinguts.

- Explicar les possibles causes de les diferències entre condicions experimentals. 


\section{Material i mètodes}

\subsection{Llista de material}

\subsubsection{Pegats transdèrmics: Nicotinell ${ }^{\circledR} 21 \mathrm{mg} / 24 \mathrm{~h}$}

Cada pegat conté 52,5 mg de nicotina en una superfície de $30 \mathrm{~cm}^{2}$ que allibera una quantitat nominal de 21 mg de nicotina. Presentació: envàs de 24 pegats (CN 658210). Laboratoris GSK, SA (AEMPS, 2019). Núm. de lot: 588500.

Llistat d'excipients:

- Pel-lícula protectora extraïble: làmina de polièster aluminitzat siliconat.

- Capa externa: làmina de polièster recoberta d'alumini.

- Capa adhesiva:

- Copolímer d'acrilat-acetat de vinil (Duro-Tak 387-2516).

- Triglicèrids de cadena mitjana (Miglytol 812).

- Solució del fàrmac: copolímer bàsic de metacrilat de butil (Eudragit E 100).

- Capa matriu:

- Copolímer d'acrilat-acetat de vinil (Duro-Tak 387-2516).

- Triglicèrids de cadena mitjana (Miglytol 812).

- Copolímer bàsic de metacrilat de butil (Eudragit E 100).

- Suport no teixit: paper de $26 \mathrm{~g} / \mathrm{m}^{2}$.

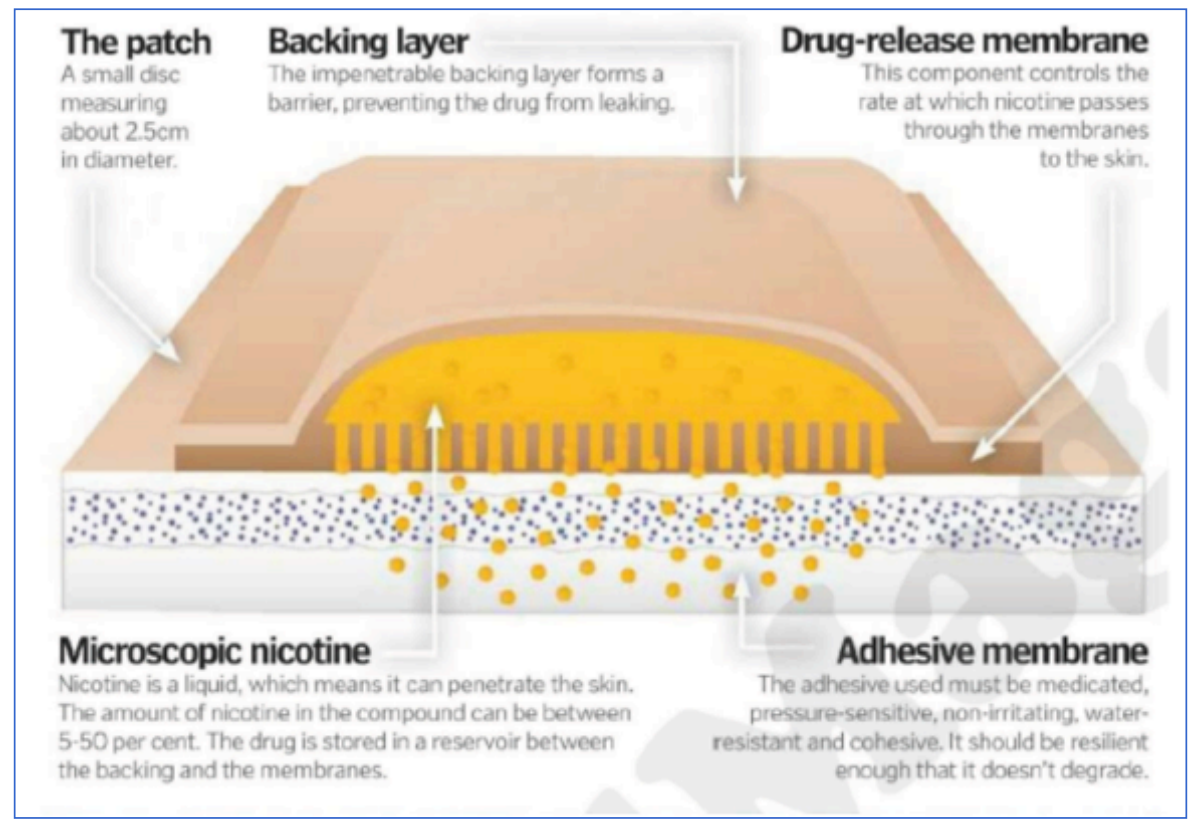

Figura 4. Diagrama de capes (How do patches help smockers?, 2019). 


\subsubsection{Estàndard de nicotina}

En aquest cas, hem utilitzat un estàndard de nicotina (Alfa Aesar, 2019) amb les especificacions següents:

$\begin{array}{lll}\text { A12398 } & \text { (S)-(-)-Nicotine, } 99 \% \\ & \\ \text { Product Number: } & \mathrm{A} 12398 \\ \text { CAS number: } & 54-11-5 \\ \text { MDL number: } & \text { MFCD00006369 } \\ \text { Molecular formula: } & \mathrm{C}_{10} \mathrm{H}_{14} \mathrm{~N}_{2} \\ \text { Molecular weight: } & 162.24\end{array}$

Figura 5. Especificacions estàndard de nicotina (Alfa Aesar, 2019).

- Aparença (color): clara, d'incolor a groc pàllid o marró.

- Forma: líquida

- Assaig (GC, gas chromatography): > 98,5\%

Núm. de lot: 10208342

Preparació de la solució mare: hem pesat 0,020 g de l'estàndard de nicotina, ho hem enrasat fins a $10 \mathrm{~mL}$ i hem obtingut una concentració de $200 \mu \mathrm{g} / \mathrm{ml}$.

\subsubsection{Solucions reguladores / medi de dissolució}

Per tenir unes condicions òptimes de solubilitat hem de conèixer la solubilitat màxima del fàrmac, especialment si és poc soluble als medis de dissolució; en aquests casos, pot ser que la concentració límit s'acosti a la solubilitat màxima, de manera que endarrereixi o inclús pari la dissolució del fàrmac (condicions SINK) (Costa i Lobo, 2001).

Els assajos s'han realitzat amb dos medis de dissolució amb diferents $\mathrm{pH}(3,0$ i 10,0) per poder comprovar l'efecte del $\mathrm{pH}$ sobre l'alliberació del fàrmac. La composició de les solucions reguladores que s'han fet servir com a medis de dissolució es detallen a la taula 2.

TAULA 2. COMPOSICIÓ DELS MEDIS DE DISSOLUCIÓ.

\begin{tabular}{|c|c|c|c|c|c|c|}
\hline & & & & & $\begin{array}{c}\text { pH } 3,0 \\
\text { A:B }\end{array}$ & $\begin{array}{c}\text { pH 10,0 } \\
\text { A:B }\end{array}$ \\
\hline $\begin{array}{c}\text { Dissolucions } \\
\text { mare }\end{array}$ & & Molaritat (M) & PM & Pes/vol. & $\%$ & $\%$ \\
\hline \multirow{3}{*}{ A } & Glicina & 0,1 & 75,07 & $750,70 \mathrm{mg}$ & & \\
\hline & $\mathrm{NaCl}$ & 0,1 & 58,44 & $584,40 \mathrm{mg}$ & 81,0 & 62,5 \\
\hline & Aigua & & & $100,00 \mathrm{~mL}$ & & \\
\hline \multirow{2}{*}{ BL } & $\mathrm{HCl} 1 \mathrm{~N}$ & 0,1 & 10 & $10,00 \mathrm{~mL}$ & 19,0 & \\
\hline & Aigua & & & $100,00 \mathrm{~mL}$ & & \\
\hline \multirow{2}{*}{ BH } & $\mathrm{NaOH}$ & 0,1 & 39,997 & $399,97 \mathrm{mg}$ & & 37,5 \\
\hline & Aigua & & & $100,00 \mathrm{~mL}$ & & \\
\hline
\end{tabular}


Edusfarm 11-12 (2019-2020), 111-134

ISSN: 1886-6271

Preparació

TAULA 3. GUIA DE PREPARACIÓ DEL MEDIS DE DISSOLUCIÓ.

\begin{tabular}{|l|c|c|c|c|c|}
\hline & Per experiència: & Per estudi: & & \\
\hline n vasos & 4 & 4 & 24 & 24 & \\
\hline Vol. vasos & $500 \mathrm{~mL}$ & $500 \mathrm{~mL}$ & $500 \mathrm{~mL}$ & $500 \mathrm{~mL}$ \\
\hline $\begin{array}{l}\text { Per preparar } \\
\mathbf{( + 1 0 0 )}\end{array}$ & $2100 \mathrm{~mL}$ & $2.100 \mathrm{~mL}$ & $12.600 \mathrm{~mL}$ & $12.600 \mathrm{~mL}$ & \\
\hline $\mathbf{A}$ & $1701 \mathrm{~mL}$ & $1.313 \mathrm{~mL}$ & $10.206 \mathrm{~mL}$ & $7.875 \mathrm{~mL}$ & \\
\hline Glicina & $12,77 \mathrm{~g}$ & $9,85 \mathrm{~g}$ & $76,62 \mathrm{~g}$ & $59,12 \mathrm{~g}$ & $135,73 \mathrm{~g}$ \\
\hline NaCl & $9,94 \mathrm{~g}$ & $7,67 \mathrm{~g}$ & $59,64 \mathrm{~g}$ & $46,02 \mathrm{~g}$ & $105,67 \mathrm{~g}$ \\
\hline BL & $399 \mathrm{~mL}$ & & $2.394 \mathrm{~mL}$ & & \\
\hline HCl 1N & $39,90 \mathrm{~g}$ & & $239,40 \mathrm{~g}$ & & $239,40 \mathrm{~g}$ \\
\hline BH & & $788 \mathrm{~mL}$ & & $4.725 \mathrm{~mL}$ & \\
\hline NaOH & & $3,15 \mathrm{~g}$ & & $18,90 \mathrm{~g}$ & $18,90 \mathrm{~g}$ \\
\hline
\end{tabular}

La capacitat màxima dels vasos és d'1 L, però com que, considerant les condicions SINK, podem utilitzar un volum de medi de dissolució de $500 \mathrm{ml}$, hem preparat $4.200 \mathrm{ml}$ de medi de dissolució per a cada experiència, ja que tenim vuit vasos.

\subsection{Llistat d'aparells}

- pH-metre: hem posat la funció de l'aparell de calibratge i hem procedit a calibrar amb tampons de pH 9,21 i 4,01.

- Espectrofotòmetre UV/VIS (ultravioleta/visible): l'hem fet servir per estimar la concentració de les nostres mostres i les rectes de calibratge. Model: GeneQuant 1300.

- Aparell de dissolució: l'aparell de dissolució utilitzat està descrit a l'apartat 3.6. El volum del vas és de $500 \mathrm{ml}$ i com a variables discriminatòries hem seleccionat la velocitat de rotació de les pales i el pH del medi. Model: Hanson SR-8, mòdul de control Validata.

\subsection{Selecció de condicions discriminants de l'estudi d'alliberació}

A l'hora de dissenyar els experiments de dissolució, hem tingut en compte els factors següents que poden influir en els resultats: solubilitat del component, volum de dissolució, velocitat de dissolució (Costa i Lobo, 2001), medi de dissolució...

És per això que hem marcat diferents variables (vegeu la taula 4) en les diferents repeticions (Costa i Lobo, 2001). 
TAULA 4. EXPERIÈNCIES I CONDICIONS EXPERIMENTALS

\begin{tabular}{|c|c|c|c|c|c|c|}
\hline Experiència & pH & $\begin{array}{l}\text { Velocitat de } \\
\text { rotació (rpm) }\end{array}$ & $\mathbf{N}$ & $\begin{array}{c}\text { Duració } \\
\text { mínima (h) }\end{array}$ & Dosi & Superfície \\
\hline 1 & Aigua & 25 & 8 & 36 & $\begin{array}{c}7 \mathrm{mg} / \mathrm{cm}^{2} \\
17,5 \mathrm{mg}\end{array}$ & $\begin{array}{l}10 \mathrm{~cm}^{2} \\
\text { calibrat }\end{array}$ \\
\hline 2 & 10 & 25 & 8 & 36 & $\begin{array}{c}21 \mathrm{mg} / \mathrm{cm}^{2} \\
52,5 \mathrm{mg}\end{array}$ & $\begin{array}{l}30 \mathrm{~cm}^{2}, \\
\text { calibrat }\end{array}$ \\
\hline 3 & 3 & 25 & 8 & 36 & $\begin{array}{c}21 \mathrm{mg} / \mathrm{cm}^{2} \\
52,5 \mathrm{mg}\end{array}$ & $30 \mathrm{~cm}^{2}$ \\
\hline 4 & $10+3$ & $25^{*}$ & $4+4$ & 36 & $\begin{array}{c}21 \mathrm{mg} / \mathrm{cm}^{2} \\
52,5 \mathrm{mg}\end{array}$ & $30 \mathrm{~cm}^{2}$ \\
\hline 5 & 10 & 75 & 8 & 36 & $\begin{array}{c}21 \mathrm{mg} / \mathrm{cm}^{2} \\
52,5 \mathrm{mg}\end{array}$ & $30 \mathrm{~cm}^{2}$ \\
\hline 6 & 3 & 75 & 8 & 36 & $\begin{array}{c}21 \mathrm{mg} / \mathrm{cm}^{2} \\
52,5 \mathrm{mg}\end{array}$ & $30 \mathrm{~cm}^{2}$ \\
\hline
\end{tabular}

La primera experiència s'ha fet per posar a punt l'aparell i la tècnica de treball. Per fer aquesta posada a punt hem fet servir uns pegats més petits, amb aigua com a medi de dissolució i amb un lot diferent dels de la resta d'assajos.

Les cinc experiències següents buscaven caracteritzar l'alliberació de nicotina dels pegats transdèrmics en les diferents condicions de treball. La quarta experiència l'hem realitzat a $25 \mathrm{rpm} i$ hem repartit la dissolució en quatre vasos amb pH 3 i quatre vasos amb pH 10 per poder tenir més replicats de cada $\mathrm{pH}$ per completar les experiències 2 i 3 i poder comparar la influència del pH en una mateixa experiència.

Per a cada experiència hem tret mostres cada hora o dues hores fins a arribar a un mínim de vint-i-quatre hores. Les mostres les hem extret amb una xeringa de $5 \mathrm{~mL}$ de capacitat i per a cada extracció hem deixat reposar la dissolució amb el volum equivalent de medi de dissolució per no tenir pèrdua de volum.

\subsection{Mètode de tractament de dades}

El test in vitro que hem fet servir té un paper molt important en el desenvolupament de la forma farmacèutica i el control de qualitat. Es pot utilitzar no només com a eina primària per controlar l'estabilitat dels productes farmacèutics, sinó també com una tècnica relativament ràpida i barata per hipotetitzar l'absorció in vivo d'una formulació.

Hi ha una gran varietat de models matemàtics desenvolupats per adaptar-se a les dades d'alliberació de fàrmacs, la majoria dels quals són equacions no lineals. L'ajust d'aquest model a les dades de dissolució es pot realitzar mitjançant programes estadístics professionals de regressió no lineal, com ara GraphPad Prism, Winnonlin-Phoenix... Però aquests programes requereixen que l'usuari defineixi l'equació manualment i proporcioni un valor inicial per a cada paràmetre per tal de realitzar el càlcul de regressió (Zhang et al., 2010).

Hi ha diferents enfocaments per avaluar la similitud entre perfils de dissolució, com el factor de diferència F1 i el factor de similitud F2, els índexs de Rescigno... Tot i que la teoria matemàtica està molt desenvolupada, no hi ha un programari que faciliti els càlculs de manera quasi automàtica. Per això hem utilitzat un programa alternatiu per ajustar els models de dissolució llestos per utilitzar: el complement d'Excel DDSolver (Zhang et al., 2010). 


\subsubsection{DDSolver}

El programari DDSolver es pot utilitzar per facilitar la modelització de les dades de dissolució amb mètodes d'optimització no lineal basats en una biblioteca de models integrada que conté quaranta models de dissolució, per simplificar la tasca d'avaluar la similitud entre els perfils de dissolució utilitzant diversos enfocaments populars, accelerar el càlcul, reduir els errors d'usuari i proporcionar informació de manera ràpida i senzilla de les dades de dissolució (Zhang et al., 2010).

\section{Model de dissolució}

Per escollir el millor model de dissolució entre els esmentats a la taula 1 hem fet servir l'opció Dissolution data modeling del programa DDSolver.

La selecció d'un model adequat per ajustar les dades de dissolució és essencial no només per a l'avaluació quantitativa de les característiques d'alliberació del fàrmac, sinó també per a la comparació dels perfils de dissolució.

Hem provat el model amb diferents equacions com: first-order, Higuchi, Korsmeyer-Peppas, Hixon-Crowell, Peppas-Sahlin ( $m$ ), Peppas-Sahlin $(0,5)$, Quadratic i Weibull i Hopfenberg. Aquestes són les equacions que es podrien adaptar millor a un model d'alliberació d'un pegat transdèrmic.

El programa DDSolver proporciona una sèrie de criteris estadístics per avaluar com s'ajusta el nostre model a les nostres dades (Zhang et al., 2010).

\section{Semblança}

En el nostre cas, per avaluar el model que s'ajusta millor hem fet servir el criteri d'informació d'Akaike (AIC), explicat a l'apartat 1.4, escollint el valor més petit; el coeficient de correlació (Robs-pre), explicat a l'apartat 1.4, escollint el valor més gran, i la versemblança gràfica de la predicció de dades directes (no residuals).

Un cop seleccionat el millor model, s'ha avaluat la semblança entre les diferents experiències. S'han fet servir algunes de les equacions descrites a l'apartat 1.5.

En el nostre cas hem fet servir el factor de semblança $f_{2}$, acceptant que valors superiors a 50 ens indiquen similitud entre corbes.

\section{Resultats i discussió}

\subsection{Estabilitat i posada a punt}

Per poder començar l'estudi hem realitzat una posada a punt (experiència 1) amb pegats més petits per calibrar i validar el mètode que hem fet servir.

També hem realitzat un estudi d'estabilitat, previ a la part experimental, per saber com hem de conservar les nostres mostres mentre es demora l'analítica. És important saber si el nostre producte es degrada en diferents situacions. Si no tenim controlades les condicions de conservació, podem obtenir uns resultats no fiables per degradació del nostre fàrmac.

Per avaluar l'estabilitat hem de tenir les nostres mostres en diferents condicions. Hem collocat un vial amb solució de nicotina amb exposició a la llum, un altre amb exposició a la calor i un altre amb exposició al fred. Els hem valorat al principi, al cap de quinze dies i al final de l'estudi per veure si hi ha diferències d'absorbància.

A partir de cada condició s'ha mesurat l'absorbància mitjançant espectrometria UV-Vis i els resultats de l'estudi sobre les condicions de conservació, tot i que hem trobat degradació en cada condició, ens indiquen que les nostres mostres s'han de guardar en fred i sense que els toqui la llum per tal que el fàrmac no es degradi. 
Comprovació de les revolucions per minut (RPM).

Hem realitzat una comprovació manual de les RPM, hem contrastat la mesura amb la dada que dona l'aparell i donem com a vàlides les mesures realitzades.

\subsection{Estudi analític de la variabilitat}

Per a la realització de les rectes de calibratge hem descartat absorbàncies superiors a 2 i inferiors a 0,100 (llei de Lambert-Beer). Hem utilitzat el coeficient de variació (CV) per avaluar la variabilitat interdia i intradia.

$$
C V=\frac{D V}{X} \times 100
$$

Equació 6. Coeficient de variació.

on $D V$ és la desviació estàndard i $X$ és la mitjana de les dades. Ens dona un resultat en percentatge que acceptarem quan sigui menor a 10.

I l'error relatiu, que és l'error absolut (diferència entre el valor exacte i la seva aproximació) dividit per la magnitud del valor exacte, és una mesura d'exactitud.

$$
\text { Error relatiu }=\frac{(\text { valor real }- \text { valor teòric })}{(\text { valor real) }}
$$

Equació 7. Error relatiu.

\subsubsection{Variabilitat interdia}

Per avaluar la variabilitat interdia hem agafat les rectes de calibratge per a cada experiència.

\section{Coeficient de variabilitat}

Hem calculat i reportat el coeficient de variabilitat entre els pendents de les rectes.

TAULA 5. COEFICIENT DE VARIABILITAT

ENTRE ELS PENDENTS DE TOTES LES RECTES

$$
\begin{array}{l|r}
\text { CV } & 9,430
\end{array}
$$

El valor de CV de 9,43 és acceptable, però és un valor molt alt. Podem dir que segurament és degut a la forma en què hem fet la recta de calibratge, ja que les rectes 1, 2, 3 i 4 han estat fetes amb menys cura que les 5 i 6, amb l'estàndard de nicotina.

\section{Error relatiu}

En general tots els valors d'error relatiu són bastant acceptables, no hi ha cap valor en valor absolut superior a 11,18 i la majoria de valors es comprenen entre 0 i 2; a mesura que disminueix la concentració, van augmentant, però tot $\mathrm{i}$ això els donem per vàlids. 


\subsubsection{Variabilitat intradia}

Per avaluar la variabilitat intradia hem realitzat un estudi amb quatre rectes de calibratge realitzades en dos dies diferents (10/4/2019 i 11/4/2019).

\section{Coeficient de variabilitat}

TAULA 6. COEFICIENT DE VARIABILITAT ENTRE ELS PENDENTS DE RECTES INTRADIA

\begin{tabular}{|l|l|l|}
\hline Recta & Dia $10 / 4 / 2019$ & Dia $11 / 4 / 2019$ \\
\hline CV & 4,412 & 6,764 \\
\hline
\end{tabular}

TAULA 7. COEFICIENT DE VARIABILITAT ABSORBÀNCIA/CONCENTRACIÓ RECTES INTRADIA

\begin{tabular}{|l|l|l|}
\hline Recta & Dia $10 / 4 / 2019$ & Dia $11 / 4 / 2019$ \\
\hline CV & 3,682 & 7,513 \\
\hline
\end{tabular}

En aquest cas, la variabilitat és molt acceptable, ja que obtenim valors més baixos de CV. Això ens indica que és millor fer totes les mesures el mateix dia i no en dies diferents, ja que la variabilitat intradia és molt més baixa que la variabilitat interdia.

\section{Error relatiu}

En general tots els valors d'error relatiu són bastant acceptables, no hi ha cap valor en valor absolut superior a 13,07 i la majoria de valors es comprenen entre 0 i 2 ; a mesura que disminueix la concentració van augmentant, però tot $\mathrm{i}$ això els donem per vàlids.

\subsection{Correccions de volum}

Per tal d'obtenir uns valors més ajustats a la realitat de la concentració de nicotina al medi a cada temps i cada vas, hem corregit la concentració tenint en compte la pèrdua per evaporació i la quantitat en volum que hi ha sota el vidre de rellotge.

\subsection{Ajust del model d'alliberació}

Per poder fer un bon ajust amb el model d'alliberació, primer hem provat amb els diferents models i el programa esmentats a l'apartat 5.5.1, amb les dades de Qcorr de cada experiència i cada vas.

Amb aquest tractament de dades hem aconseguit trobar el model que s'ajusta millor, a partir de l'AIC, el coeficient de correlació Robs-pred, l'AUC, l'MDT i l'observació de gràfiques, esmentats a l'apartat 3.4. 


\subsubsection{Criteri d'informació d'Akaike}

Hem escollit el valor més baix de cada experiència i cada vas per escollir el model que s'ajusta millor. Segons els resultats obtinguts ( 6 vasos de 8 ) i seguint aquest criteri, el model que s'adapta millor a les nostres dades és el de Peppas-Sahlin amb una m de 0,5.

\subsubsection{Coeficient de correlació}

Hem escollit el valor més alt de cada experiència i cada vas per escollir el model que s'ajusta millor. Segons els resultats obtinguts ( 5 vasos de 8 ) i seguint aquest criteri, el model que s'adapta millor a les nostres dades és el de Peppas-Sahlin amb una $m$ de 0,5.

\subsubsection{Observació visual de gràfiques}

Hem escollit el gràfic que comparteix més punts amb la recta real per escollir el model que s'ajusta millor. Segons els resultats obtinguts i seguint aquest criteri, el model que s'adapta millor a les nostres dades és el de Peppas-Sahlin amb una m de 0,5.

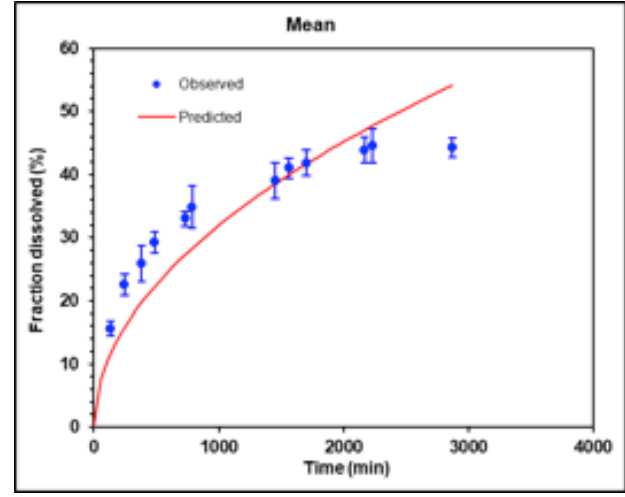

Figura 6. Higuchi corba mitjana. Experiència 3.

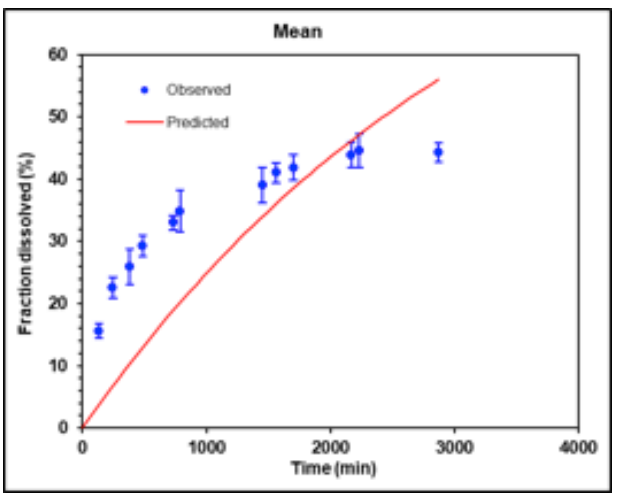

Figura 8. First-order corba mitjana. Experiència 3.

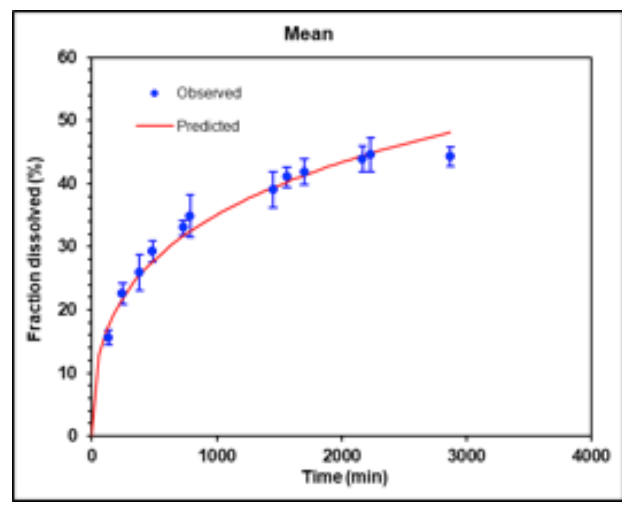

Figura 7. Weibull corba mitjana. Experiència 3

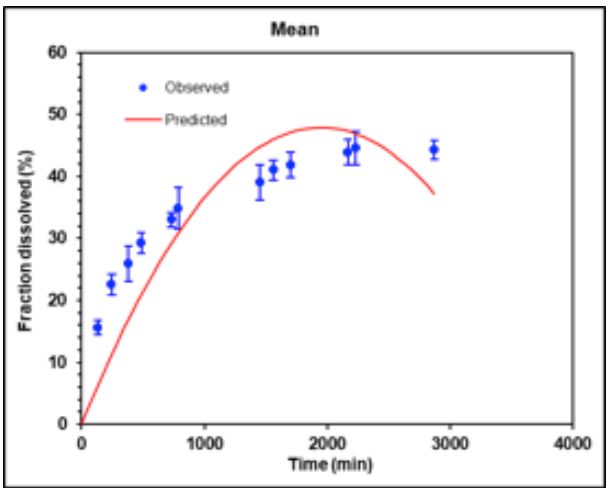

Figura 9. Quadràtic corba mitjana. Experiència 3. 


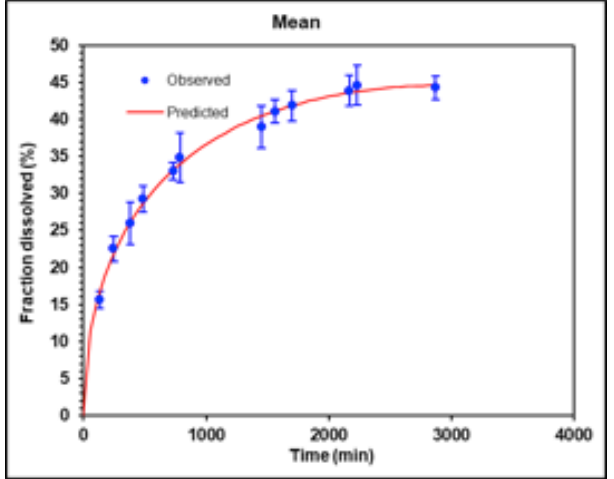

Figura 10. Peppas-Sahlin $(m=0,5)$ corba mitjana. Experiència 3.

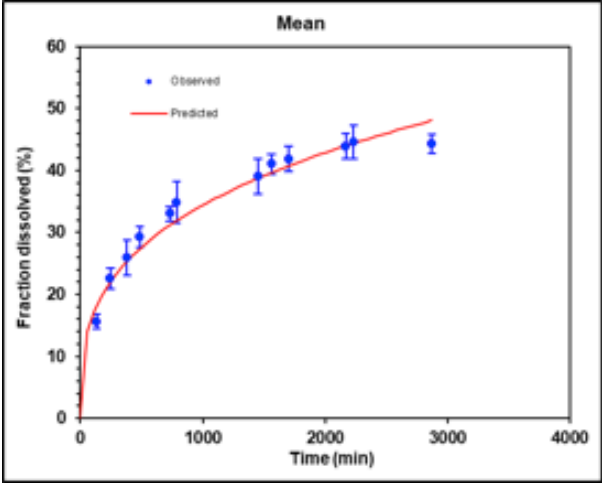

Figura 11. Korsmeyer-Peppas corba mitjana. Experiència 3

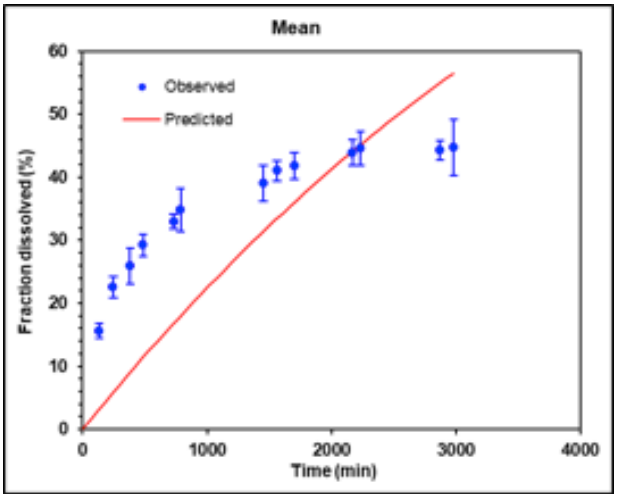

Figura 12. Hopfenberg corba mitjana.

Experiència 3.

\subsection{Obtenció de l'equació definitiva}

Seguint, doncs, els passos esmentats als apartats 6.3 i 6.4 hem arribat a la conclusió que les nostres dades segueixen el model de Peppas-Sahlin amb una $m$ de 0,5, que es descriu amb l'equació següent (descrita a l'apartat 3.3.8):

$$
F(\%)=k 1 \times t^{m}+k 2 \times t^{2 m}
$$

on $m$ pren el valor de 0,5 , ja que es tracta d'una formulació laminar.

\begin{tabular}{|c|c|c|c|}
\hline \multicolumn{4}{|c|}{ Diffusion exponent and solute release mechanism } \\
\hline \multicolumn{3}{|c|}{ Diffusion exponent $(m)$} & \multirow[t]{2}{*}{ Mechanism } \\
\hline Film & Cylinder & Sphere & \\
\hline 0.50 & 0.45 & 0.43 & $\begin{array}{l}\text { Fickian } \\
\text { diffusion }\end{array}$ \\
\hline $\begin{array}{c}0.50<m \\
<1.00\end{array}$ & $\begin{array}{r}0.45<m \\
<0.89\end{array}$ & $\begin{array}{r}0.43<m \\
<0.85\end{array}$ & $\begin{array}{l}\text { Anomalous } \\
\text { transport }\end{array}$ \\
\hline 1.00 & 0.89 & 0.85 & $\begin{array}{l}\text { Case-II } \\
\text { transport }\end{array}$ \\
\hline
\end{tabular}

Figura 13. Significats del valor de $m$ (Peppas and Sahlin, 1989). 
Per prosseguir amb el tractament de dades i com que en cap cas podem assegurar que l'experiència arriba a una asímptota, hem calculat la $Q_{24 \mathrm{~h}}$ per a cada experiència i cada vas utilitzant els valors de $K 1$ i $K 2$ obtinguts de la selecció del model.

$$
Q 24=k 1 \times 1440^{0,5}+k 2 \times 1440
$$

Quan hem obtingut la Q24 de cada vas i cada experiència, hem calculat el \% de fàrmac que s'ha alliberat en cada temps respecte a la quantitat alliberada al cap de 24 hores.

$$
F \% 24=\frac{Q c o r r}{Q 24} \times 100
$$

Així, doncs, obtenim un percentatge equivalent per a cada experiència. Un cop obtinguts els percentatges, hem utilitzat el programa DDSolver per trobar una equació de Peppas-Sahlin $(m=0,5)$ més acurada per a cada experiència i cada vas i comparables entre elles.

\subsection{Fracció de fàrmac que segueix la llei de Fick}

L'equació de Peppas-Sahlin ens permet identificar el percentatge d'alliberació que es regeix per la llei de Fick; la resta és per erosió (Peppas i Sahlin, 1989). Per calcular-lo hem utilitzat l'equació següent, en la qual tenen importància els valors de $K 1$ i $K 2$.

$$
F=\frac{1}{1+\frac{k_{2}}{k_{1}} t^{m}}
$$

Equació 4. Percentatge de fàrmac alliberat que segueix la llei de Fick (Peppas and Sahlin, 1989).

Si el valor de $K 2<<<K 1$ vol dir que l'alliberació es principalment per difusió (Peppas i Sahlin, 1989). Aplicant l'equació, podem calcular aquest percentatge i obtindrem els resultats reflectits en el gràfic següent.

A mesura que passa el temps, la formulació pot perdre les seves propietats i per això és útil calcular el percentatge d'alliberació per difusió (\% Fick) que hem obtingut a cada temps.

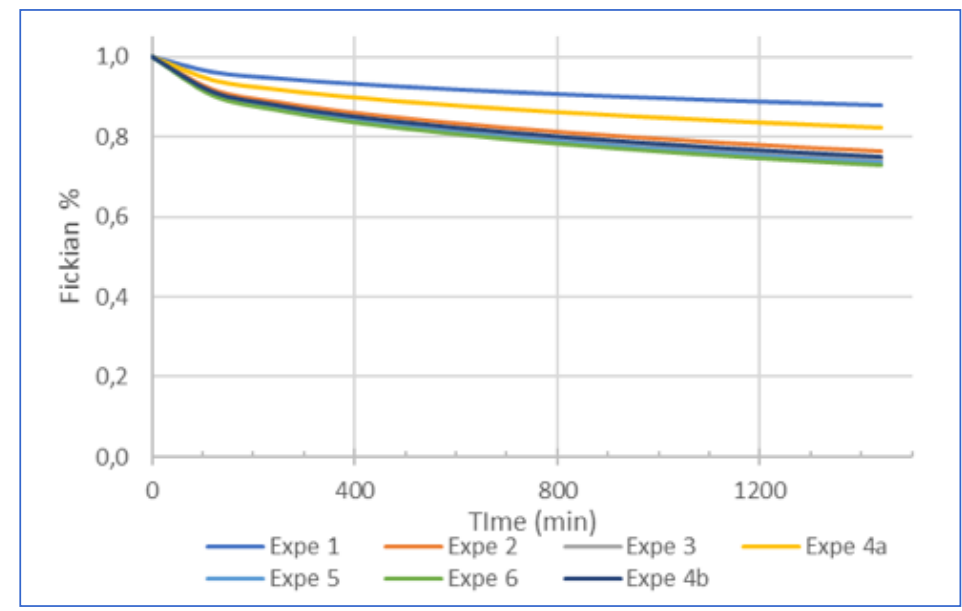

Figura 14. Gràfica de les $F$ mitjanes de les diferents experiències. 
Basant-nos en la representació de la figura 14, podem dir que majoritàriament la dissolució del fàrmac és per difusió. Tot i això, en les dues primeres hores el valor del component de difusió disminueix en gran manera a causa de l'erosió; després disminueix d'una manera més suau fins a arribar a aproximadament un 75 \% de dissolució per la llei de Fick i un 25 \% per erosió. Això pot ser degut a que es tracta d'una formulació d'alliberació prolongada i en el primer moment necessitem administrar fàrmac ràpidament per assolir nivells plasmàtics.

Basant-nos en els resultats obtinguts, podem arribar a la conclusió que la resta de models no s'ajusten tan correctament a la nostra dissolució com el de Peppas-Sahlin, ja que aquest marca dues tendències: primer una alliberació ràpida per difusió i després una alliberació per erosió (que es consideren equacions additives).

L'equació de Korsmeyer-Peppas no és del tot adequada, ja que quan fem el tractament de dades amb el DDSolver ens dona un valor de $n$ aproximadament de 0,4 (proper a 0,5, que significa difusió passiva), però no el 0,5 que li pertoca. Tampoc no és adequada l'equació de Hopfenberg perquè ens descriu tan sols alliberació per erosió de la superfície amb una $n=1$, ja que seria per làmines.

També cal comentar que hi ha un lleuger augment de la proporció de difusió a un pH 10 i menys erosió.

\subsection{F2}

Les dades que hem fet servir per calcular l'índex de semblança (f2) són les que hem predit per al cap de 24 hores a partir de les equacions, ja que en no tenir un sistema de mostreig automàtic no hem tingut sempre els mateixos temps. També cal esmentar que per calcular el factor de semblança es necessiten 12 rèpliques per a cada condició experimental que hem complert per al cas de $25 \mathrm{rpm}$, però no per al de 75 rpm (Vinod P. Shah et al., 1999).

TAULA 8. CÀLCUL DE F2 PER A LES CORBES MITJANES DE LES DIFERENTS CONDICIONS EXPERIMENTALS

\begin{tabular}{|c|c|c|c|c|}
\hline F2 & pH 3 - 25 rpm & pH 10 - 25 rpm & pH 3 - 75 rpm & pH 10 - 75 rpm \\
\hline pH 3 - 25 rpm & & 79,64 & 91,25 & 96,06 \\
\hline pH 10 - 25 rpm & & & 72,16 & 74,94 \\
\hline pH 3 - 75 rpm & & & & 97,98 \\
\hline
\end{tabular}

En general podem dir que dues rectes són semblants quan el valor de $f_{2}$ és superior a 50. Podem dir que totes les nostres rectes són acceptablement similars, segons la taula 8.

Per tant, observant els resultats de l'índex de semblança podem dir que són acceptables, que les dades es poden comparar entre elles i que la tria del model ha estat correcta.

\subsection{Efecte del pH i la velocitat sobre l'alliberació}

Per estudiar l'efecte del pH i la velocitat de les pales sobre l'alliberació hem agrupat les experiències segons les condicions i ens han quedat quatre grups de dades. 


\section{Observació gràfica}

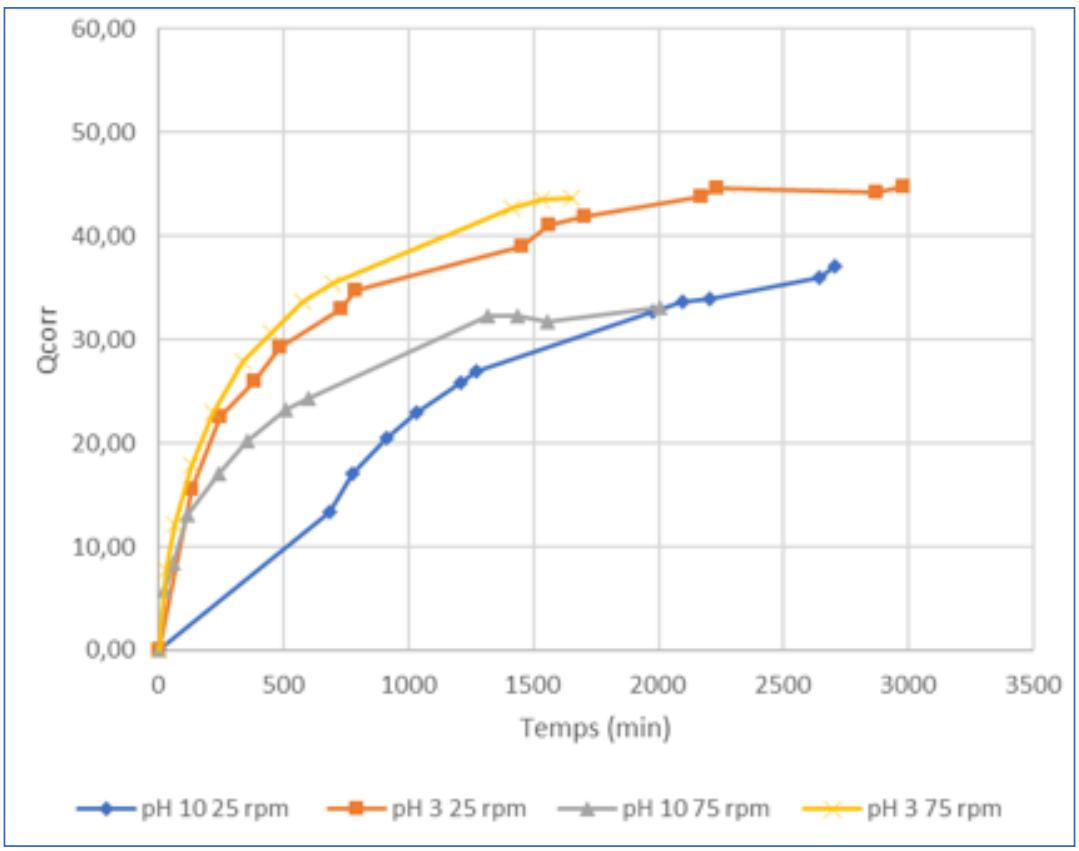

Figura 15. Gràfica $Q$ corregides vs. temps (min) de les diferents condicions experimentals.

Segons el gràfic de la figura 19, podem intuir que amb un pH més àcid (pH 3) el pendent de la primera fase és més elevat que amb un $\mathrm{pH}$ més bàsic $(\mathrm{pH} 10)$. Per tant, que l'alliberació de fàrmac $\mathrm{amb}$ un $\mathrm{pH} 3$ serà més ràpida. Si ens fixem en la velocitat de les pales d'agitació (rpm), en comparar que les experiències d'un mateix $\mathrm{pH}$ observem que la que té una velocitat d'agitació més ràpida també té una alliberació més ràpida, cosa que es veu molt clarament en el cas amb pH 10 i no tant en el cas amb pH3.

Podem confirmar aquestes dades amb la comparació gràfica de l'experiència 4 (amb dos $\mathrm{pH}$ diferents):

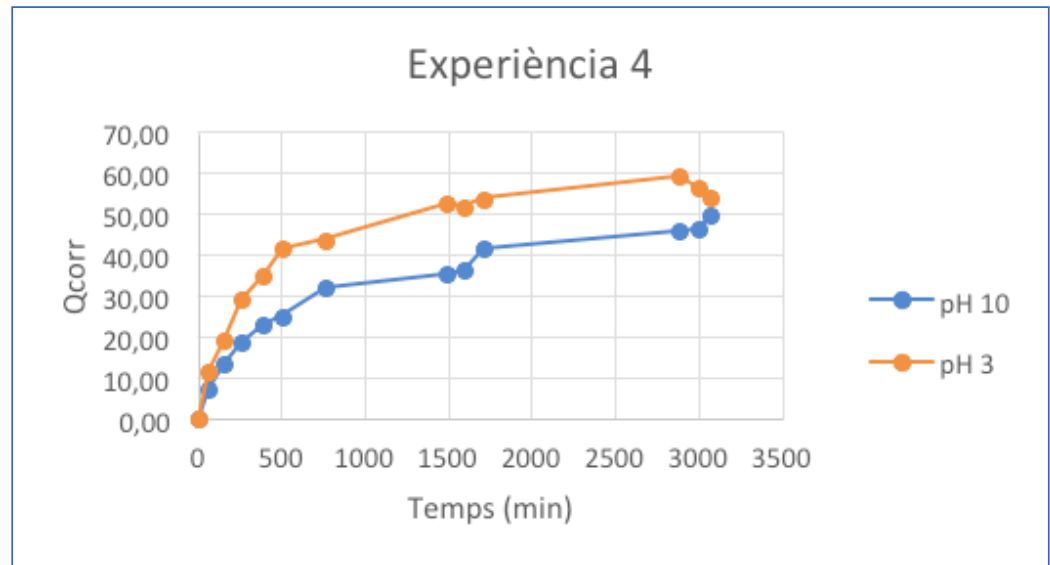

Figura 16. Gràfica $Q$ corregides (mg) vs. temps (min) de l'experiència 4. 
TAULA 9. T75 RESPECTE A Q24H DE LES DIFERENTS CONDICIONS EXPERIMENTALS

\begin{tabular}{|l|c|c|c|}
\multicolumn{1}{c|}{$\begin{array}{c}\text { Condicions } \\
\text { experimentals }\end{array}$} & Mitjana (temps, min) & SD & CV \\
\hline pH 3 / 25 rpm & 569 & 63,18 & 11,08 \\
\hline pH 10 / 25 rpm & 632 & 48,53 & 7,67 \\
\hline pH 3 / 75 rpm & 534 & 15,19 & 2,84 \\
\hline pH 10 / 75 rpm & 551 & 106,70 & 19,35 \\
\hline
\end{tabular}

Segons la taula 9, els pegats en un medi de dissolució àcid (pH3) tarden menys a alliberar la mateixa quantitat de fàrmac que els que estan en un medi de dissolució bàsic (pH10).

La velocitat de rotació de les pales de l'aparell de dissolució influeix en l'alliberació de fàrmac de la forma farmacèutica. Així, doncs, com més ràpida sigui la rotació de les pales, més ràpida serà també l'alliberació.

Si parlem d'una velocitat de $25 \mathrm{rpm}$, la mitjana que tarda un pegat a alliberar el $75 \%$ de fàrmac respecte a les 24 hores és de 10 hores; en canvi, si parlem de 75 rpm, són 9 hores.

\section{AUC}

L'àrea sota la corba s'ha calculat fins a les 24 hores.

TAULA 10. T-STUDENT DIFERÈNCIES DE AUC

\begin{tabular}{|l|c|c|}
\hline \multicolumn{1}{|c|}{ t de Student } & pH $\mathbf{1 0}-\mathbf{2 5} \mathbf{~ r p m}$ & pH $\mathbf{3}-\mathbf{7 5} \mathbf{~ r p m}$ \\
\hline pH 3 $\mathbf{- 2 5} \mathbf{~ r p m ~}$ & $p<0,01$ & $p>0,01$ \\
\hline pH 10 - 75 rpm & $p>0,01$ & $p<0,01$ \\
\hline
\end{tabular}

La prova estadística t de Student ens diu si els resultats són estadísticament significatius. Ens proporciona un valor de $P$ que ens permet escollir un nivell de significació; en el nostre cas, considerem estadísticament significatius valors de $P$ menors de 0,01 .

Segons els resultats obtinguts en l'estudi estadístic, hi ha diferències significatives entre els valors mitjans de l'AUC de les experiències segons el $\mathrm{pH}$, però no segons la velocitat.

\section{MDT}

L'MDT és el temps mitjà que tarda a dissoldre's la forma farmacèutica.

TAULA 11. MITJANES DE MDT DE LES DIFERENTS CONDICIONS EXPERIMENTALS

\begin{tabular}{|l|c|c|}
\hline \multicolumn{1}{|c|}{ MDT } & Mitjana & DS \\
\hline pH 3 - 25 rpm & 3,90 & 1,71 \\
\hline pH 10 - 25 rpm & 4,09 & 0,80 \\
\hline pH 3 - 75 rpm & 3,10 & 0,12 \\
\hline pH 10 - 75 rpm & 4,12 & 1,26 \\
\hline
\end{tabular}


Segons els resultats obtinguts, el temps estadístic que tarda a dissoldre's el $50 \%$ de les molècules de la dosi coneguda de la formulació és d'aproximadament 3 o 4 hores.

\subsubsection{Efecte del pH sobre l'alliberació}

Com ja hem dit anteriorment, la nicotina presenta uns pKa de 8,0 i 3,1; per tant, podem dir que és una base dèbil ionitzable, i per això hem considerat que el pH influeix en el perfil d'alliberació.

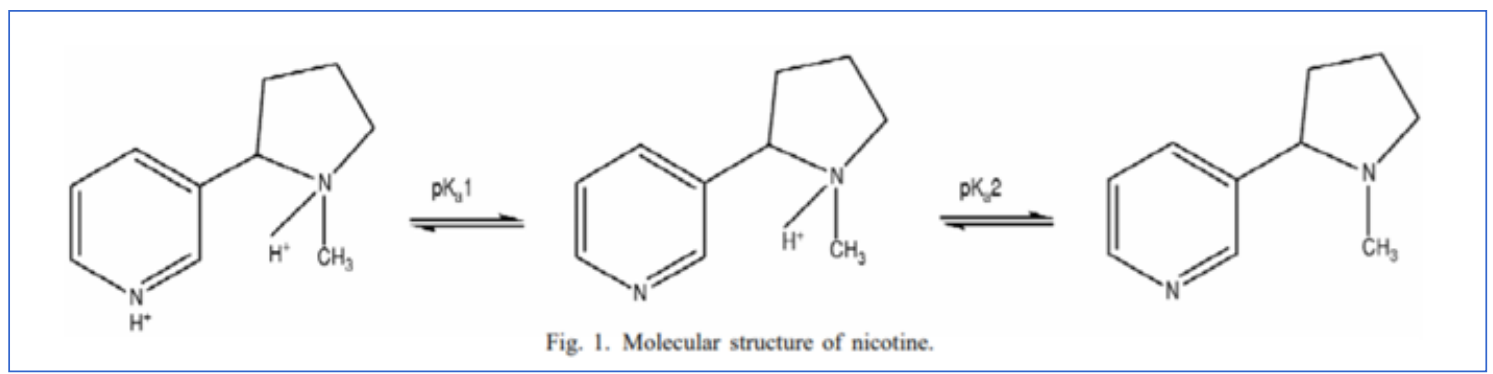

Figura 17. Ionització de la nicotina (Mørck Nielsen i Rømer Rassing, 2002).

En la figura 17 podem veure l'estructura química de la nicotina. Depenent del $\mathrm{pH}$ del medi de dissolució, tindrem una forma o una altra: com més àcid sigui el $\mathrm{pH}$, més protonada estarà la molècula (ionitzada), i com més bàsic sigui el pH, menys ionitzada estarà la molècula (més lipòfila).

$\mathrm{A}$ un $\mathrm{pH}$ de 7,4 la molècula de nicotina es troba majoritàriament monoprotonada; a un pH de 8,1, majoritàriament no ionitzada o lliure, i a un $\mathrm{pH}$ de 5,5, la quantitat de base lliure o de molècula no ionitzada és l'1 \% (calculat amb l'equació de Henderson-Hasselbalch) (Mørck Nielsen i Rømer Rassing, 2002).

\section{Influència del polímer acrílic EUDRAGIT® E 100}

L'Eudragit@ E 100 és un copolímer catiònic a base de 2-dimetilaminoetilmetracrilat i $n$-nutilmetacrilat que presenta un pes molecular mitjà de $135.000 \mathrm{i}$ una solubilitat dependent del pH.

Es dissol a l'estómac, amb un pH àcid, a causa de la formació de sals, que s'inflen per sobre d'un pH 5, de manera que augmenten la permeabilitat a l'aigua (Evonik, 2019) i permeten l'alliberació de fàrmac per dissolució.

S'aplica en forma de solució orgànica dissolta en isopropanol. Les seves pelllícules de protecció o aillament són molt efectives contra la humitat i l'oxigen, però sobretot per modular la dissolució de fàrmac segons el $\mathrm{pH}$ del medi.

En el cas dels pegats de Nicotinell ${ }^{\text {, }}$, la solució de fàrmac està dispersa en Eudragit@ E 100, cosa que podria influir en l'alliberació de nicotina, ja que en $\mathrm{pH}$ àcids Eudragit es pot dissoldre i permet augmentar la permeabilitat del fàrmac, és a dir, l'alliberació de nicotina al medi de dissolució.

La molècula de nicotina a un $\mathrm{pH}$ molt àcid $(\mathrm{pH} 3)$ es troba en forma ionitzada, biprotonada. Segons els resultats, podem arribar a la conclusió que, com més àcid sigui el pH del medi de dissolució, o més ionitzada estigui la molècula i més hidrosoluble sigui, més ràpida podrà ser l'alliberació de nicotina del pegat. Per tant, la dissolució més ràpida a $\mathrm{pH} 3$ que hem constatat es veurà influïda per la hidrosolubilitat de la nicotina, i no per la dissolució d’Eudragit. 


\subsubsection{Efecte de la velocitat sobre l'alliberació}

La velocitat de dissolució és directament proporcional al coeficient de difusió i inversament proporcional al gruix de la pelllícula $(h)$ (Costa i Lobo, 2001). Doncs, segons les dades presentades a l'apartat 6.8, podem dir que la velocitat d'alliberació està condicionada per la velocitat de rotació de les pales. Així, com més ràpida sigui la velocitat de rotació de les pales, més ràpida serà l'alliberació. Per tant, podem dir que la velocitat de les pales està relacionada amb una corba de dissolució més ràpida. Tot i això, la variació no és significativa i, per tant, no es pot atribuir a canvis en la velocitat de dissolució deguts a la velocitat d'agitació. Aquesta influència és molt menor que la del pH.

\section{Conclusions}

És molt important tenir en compte l'alliberació del fàrmac en funció de diferents variables experimentals a l'hora de formular una forma farmacèutica. En aquest estudi de condicions extremes s'ha pogut observar que, en la solució reguladora, el pH influeix en la dissolució de la nicotina i en el seu grau de ionització. S'ha trobat que a un $\mathrm{pH} 3$ la nicotina s'allibera del pegat més ràpidament que a un pH 10, probablement a causa de la ionització de la molècula i a la seva millor hidrosolubilitat.

En estudis posteriors que es puguin fer, a l'hora de permear la pell necessitem que el fàrmac estigui en forma no ionitzada. És per això que hi ha moltes formulacions per a la TSN que es tamponen a un pH alcalí, per augmentar l'absorció i, així, la biodisponibilitat.

D'altra banda, s'ha trobat que la velocitat d'agitació no té cap efecte significatiu sobre la velocitat de dissolució dels pegats.

En el nostre cas, el model que s'adapta millor a l'alliberació de pegats Nicotinell@ és el de Peppas-Sahlin amb una $m$ de 0,5 . Aquesta equació ens indica el mecanisme d'alliberació del fàrmac als pegats, que majoritàriament és per difusió passiva, però també hi participa el component d'erosió a un nivell no superior al $25 \%$.

Mitjançant l'índex de semblança comprovem que les nostres dades es poden comparar, que el model que hem escollit és acceptable i que el tractament de les dades ha estat correcte.

En conclusió, basant-nos en els resultats de l'AUC, l'MDT, T75 i l'observació gràfica de les diferents condicions experimentals, podem dir que en l'assaig d'alliberació de nicotina de pegats transdèrmics que hem realitzat, predomina generalment la difusió passiva sobre l'erosió de la matriu. Hi influeixen positivament les variables experimentals per a pH baixos i menys significativament la velocitat de rotació de les pales.

\section{Bibliografia}

AEMPS (2019) FICHA TECNICA pegats de nicotina Nicotinell. Disponible a: http://cima.aemps.es/cima/ pdfs/es/ft/68303/68303_ft.pdf (accés: 14 març 2019).

AlFa Aesar (2019) «Certificate of analysis Nicotine S(-)».

Benowitz N.L., HukKanen J., JaCoB P. (2009) Nicotine Chemistry, Metabolism, Kinetics and Biomarkers. In: Henningfield J.E., London E.D., Pogun S. (eds) Nicotine Psychopharmacology. Handbook of Experimental Pharmacology, vol 192. Springer, Berlin, Heidelberg .

Council of Europe. European Pharmacopeia 9 ed «2.9.3 DISSOLUTION TEST FOR SOLID DOSAGE FORMS» (2018).

Costa, P., Loво, J.M.S. (2001) «Influence of dissolution medium agitation on release profiles of sustainedrelease tablets». Drug Development and Industrial Pharmacy, 27(8), pp. 811-817. doi: 10.1081/ DDC-100107244.

Costa, P., MANUEL, J., LoBo, S. (2001) «Modeling and comparison of dissolution profiles». European Journal of Pharmaceutical Sciences. doi: S0928-0987(01)00095-1.

Evonic Eudragit E 100 technical specifications (2019). 
How do patches help smockers? (2019). Disponible a: https://howitdoeswork.blogspot.com/2014/09/ how-do-patches-help-smockers.html (accés: 7 maig 2019).

Li M., TAN H. (2019) «Technical note: Comparison of USP Apparatus 5 and 7 for In Vitro Drug Release from Nicotine Transdermal Systems». Dissolution Technologies (EUA, Teledyne Hanson Research), 26(3), pp. 68-71.

Mørck Nielsen, H., RøMer RAssing, M. (2002) «Nicotine permeability across the buccal TR146 cell culture model and porcine buccal mucosa in vitro: effect of $\mathrm{pH}$ and concentration». European Journal of Pharmaceutical Sciences. doi: S0928-0987(02)00083-0.

Peppas, N., SAhlin, J. (1989) «A simple equation for the description of solute release. III. Coupling of diffusion and relaxation». International Journal of Pharmaceutics, 57, pp. 169-172. doi: 10.1016/03785173(89)90306-2.

Rescigno, A. (1992) «Rescigno Bioequivalence». Pharmaceutical Research, 9(7), pp. 925-926. doi: 07248741/92/0700-0925\$06.50/0.

Vinod P. Shah. et al. (1999) «Dissolution Profile Comparison Using Similarity Factor, f2». Dissolution Technologies, 6(3),p. 15. doi: 10.14227/DT060399P15.

ZHANG, Y. et al. (2010) «DDSolver: An Add-In Program for Modeling and Comparison of Drug Dissolution Profiles». The AAPS Journal, 12(3), pp. 263-271. doi: 10.1208/s12248-010-9185-1. 